\title{
The ECA study: what next?
}

\author{
LEE N. ROBINS
}

\section{DESCRIPTION OF THE ECA}

The Epidemiological Catchment Area (ECA) project was motivated by the experience of the United States President's Commission on Mental Health in 1978 (The President's Commission, 1978). When the Commission looked for figures on which to base estimates of the need for mental healt care and information about underserved populations, available data were found to be woefully inadequate. Existing surveys of the general population were not specific with respect to what disorders were present nor how long they had existed.

The ECA project began in 1978 with construction of the Diagnostic Interview Schedule (DIS) (Robins et al., 1979), an instrument designed to allow lay interviewers, after a brief training period, to ask all the questions needed to evaluate most of the disorders in what was soon to become the standard US nomenclature, the Diagnostic and Statistical Manual, Third Edition (DSM-III) of the American Psychiatric Association (APA, 1980), as well as two other widely used systems, the Research Diagnostic Criteria (Spitzer et al., 1978) and the Washington University (Feighner) criteria (Feighner et al., 1972). The interview was designed to mimic the behavior of a psychiatrist conscientiously evaluating each of the criteria listed for these systems. Like a clinician, the interview was to dismiss complaints of no clinical significance and rule out symptoms fully explained by physical conditions or the ingestion of alcohol and drugs. Scoring was carried out by computer.

In addition to the diagnostic questions, the inter-

\footnotetext{
Indirizzo per la corrispondenza: Professor L.N. Robins, Department of Psychiatry, School of Medicine, Washington University, 4940 Children's Place, St. Louis, Missouri 63110 (USA).

Fax $(+1)$ 314-362.2470.
}

view included standard questions about demographic status and the utilization of health services for both physical disease and emotional or mental problems. Other questions, about life events, health, and social supports, were allowed to vary between sites.

The samples selected were probability samples of the adult general population in selected mental health catchment areas in 5 cities and their environs, and included both those residing in private residences and in institutions. The initial interview was carried out with 20,000 persons, who were reinterviewed at 6 months and at one year. The results were weighted by age, sex, and race to represent the United States as a whole as of 1980 .

\section{THE MAJOR FINDINGS}

This ambitious project succeeded in completing interviews with $75 \%$ to $80 \%$ of the target samples for the first interview, and with more than $80 \%$ of those interviewed initially at the final interview. When subjects were unable to do interviews themselves because of illness, a proxy interview was conducted with a caretaker. Comparison of results across the sites showed that the interview produced very comparable results in each location, suggesting that it was reliable.

The study produced a host of interesting findings (Robins \& Regier, 1991), including the approximately equal frequency of disorder between the sexes and low rates both of current disorder and disorder over the whole lifetime reported by the elderly. The presence of any disorder was found to predict the presence of any other disorder, but especially strong associations were found between panic disorder and depression, and between substance abuse and 
antisocial personality. All persons with somatization disorder had other disorders as well.

First symptoms were recalled as having occurred considerably earlier than the literature would lead one to expect. Phobias were of particularly early onset, almost all beginning in childhood.

Treatment rates were low, even though the studies were conducted in the vicinity of medical centers, where the treatment opportunities were considerably greater than in the country as a whole. The only disorder for which virtually all those affected sought treatment was somatization disorder. A large proportion of those with panic disorder came to treatment, probably because they suspected heart disease, but schizophrenia and depression remained untreated in a substantial minority of cases, and still less frequently treated were phobias and substance abuse.

The most common disorders were alcohol-related disorders and phobias. Depression was only about as common as drug abuse, but it was clear why the psychiatric community thought it more common than these disorders: it came to treatment much more frequently.

The attempt to study incidence rates by repeating the interview one year later revealed two facts: first, the early onset of most disorders explains in part the fact that the number of new cases in a population with a median age of 40 was very small, making incidence rates unreliable (Eaton et al., 1989). Second, there was considerable denial at the second interview of ever having had symptoms reported at the first interview. This finding has been replicated in several other panel studies, which used other diagnostic instruments (Helzer et al., 1981; Bromet et al., 1986; Rice et al., 1992), both highly structured and only semistructured. It appears that this decline in frequency with which symptoms are reported in a second interview is independent of the type of interview and the training of the interviewer.

\section{Further developments prompted by the ECA}

The ECA experience has led to replications of its study design in many parts of the world, necessitating translation of the DIS into many languages. It has also led to elaborations and refinements of the diagnostic tools and to the creation of new diagnostic instruments similar to the DIS.
Among the settings in which ECA-like studies have been done using the DIS (in translation when necessary) are Puerto Rico (Canino et al., 1987), Taiwan (Hwu et al., 1990), Canada (Edmonton [Bland et al., 1988] and Quebec [Kovess \& Fournier, 1990]), Germany (Wittchen et al., 1991), South Korea (Lee, 1992), Hong Kong (Chen, 1989), China (Shanghai [Wang et al., 1992]), Iceland (Stefansson, 1991), New Zealand (Wells et al., 1991), Lebanon (Karam et al., 1991) and the United States (Colorado [Ciarlo et al., 1992]). These sites have been able to compare their results to the results of the ECA. For most disorders, considerable similarity of rates has been found. Alcohol disorders are the disorders that appear to vary most by site, reflecting differences in drinking practices.

To train researchers to use the DIS in these and many other studies, training courses have been given twice a year in St. Louis. The St. Louis group also updated the DIS when a revision of the Diagnostic and Statistical Manual (DSM-III-R) was issued in 1987 (Robins et al., 1989). That update elaborated the information about when symptoms first and last appeared in order to be able to say at what age all criteria were first fulfilled, and in what year the full display of the criteria was last apparent. A data entry, data cleaning, and scoring program for the personal computer was created to support the updated revision (Marcus et al., 1990).

Two versions of the DIS (Blouin, 1991; Marcus et al., 1991) have been constructed for computerized administration. Administration by computer offers a number of advantages. First, it drastically reduces the requirements for interviewer training, because the rules taught during training are built into the computer program. Second, it allows self-administration for literate respondents. Third, its menu allows selecting only certain diagnoses for studies that do not need the full range of diagnoses. Fourth, computer presentation is necessarily completely standardized, removing inter-interviewer variation. Finally, it saves time and errors associated with data entry, and provides scores immediately on completing the interview.

The second computer version, the computerized Quick DIS, checks after each question answered to see whether the criterion it serves can be definitively ruled in or out. If the criterion is positive, it skips to the next criterion; if the required criterion is negative, it skips to the next diagnosis. If no decision can be made, the next question in the standard interview is presented. This short version reduces time required 
to reach a diagnostic decision to about half the duration using the full DIS, and shares all the other advantages of a computerized interview. Of course, it does not produce a full symptom or criteria profile because many questions are skipped.

Inspired by the format of the DIS, the WHONIH Task Force on Assessment Instruments has sponsored the creation of a similarly structured interview, the Composite International Diagnostic Interview (CIDI) (WHO, 1993a), which evaluates diagnostic criteria of ICD-10 as well as DSM-III-R. Like the DIS, it has a data entry, cleaning, and scoring program for the personal computer. As was done for the DIS, two computerized versions have been created, the CIDI-AUTO (WHO, 1993b) and the CIDI-Quick (WHO, 1993c).

\section{WHAT NEXT}

There are developments afoot both with respect to new studies in the ECA mold and further developments in instruments.

$A$ Children's ECA. The ECA studied adults 18 and older. The National Institute of Mental Health hopes next to support a similar study of children. To this end, the Institute has sponsored the creation and testing of the DIS for Children (DISC) (National Institute of Mental Health, 1992).

DIS developments. The next step in the DIS's development will be the addition of questions and computer scoring programs needed to make diagnoses according to DSM-IV, the revision of the current Manual due to be published in 1994. Once these have been written, they will need to be tested for reliability and validity.

In addition to expanding the DIS's coverage, there will be efforts to improve its performance. While the DIS makes estimates of the rates of the lifetime and current frequencies of disorders, we know that its estimates are flawed because of recall errors. Methods of improving recall by linking recall to memorable life events and asking respondents to verify the order in which symptoms appeared will be explored and evaluated.

The DIS also lacks the ability to describe the course of disorder or its severity in detail. It tells us when the disorder began and when it last appeared, but it does not tell us whether the disorder was continuously present between those dates. The ECA ex- plored lifetime and recent treatment for emotional and mental disorders, but did not link treatment to specific disorders except by asking, with respect to each disorder, whether its symptoms had ever been reported to a doctor. No other evidence for disability was obtained. Better indicators are needed both for remission and relapses and for the degree of disability associated with specific disorders. These additions will make it more feasible to link diagnosis to need for treatment. If we also add measures of the willingness of the respondent to participate in treatment for the disorders affecting him or her, the DIS will become much more effective in estimating how much unmet demand for care exists, and how demand is related to the persistence and severity of disorder.

An Auxiliary Interview. In addition to estimating need for care for specific disorder among specific demographic groups, the ECA attempted to draw some inferences about possible risk factors for disorder. However, the range of possible risk factors assessed was narrow, and they were not dated. As a result, it could not be determined definitively whether they preceded the occurrence of the disorder and, if so, what the "incubation period» was between exposure to a risk factor and the development of symptoms. A more detailed history of possible risk factors is needed.

Thus the next steps in preparing for a possible repetition of an ECA-like study will be the updating and improvement of existing instruments and creating new accessory instruments to provide a more complete picture of the causes and course of psychiatric disorders.

\section{REFERENCES}

American Psychiatric Association (1980). Diagnostic and Statistical Manual of Mental Disorders (DSM III) (3rd ed.). American Psychiatric Association: Washington DC.

Bland R.C., Newman S.C. \& Orn H. (1988). Epidemiology of Psychiatric Disorders in Edmonton. Acta Psychiatrica Scandinavica, Supplementum No. 338, vol. 77.

Blouin A. (1991). The C-DIS. The C-DIS Management Group: Ottawa.

Bromet E.J., Dunn L.O., Connell M.M., Dew M.A. \& Schulberg H.C. (1986). Long-term reliability of diagnosing lifetime major depression in a community sample. Archives of General Psychiatry 43, 435-440.

Canino G.J., Bird H.R., Shrout P.E., Rubio-Stipec M., Bravo M., Martinez R., Sesman M. \& Guevara L.M. (1987). The prevalence of specific psychiatric disorders in Puerto Rico. Archives of General Psychiatry 44, 727-735. 
Chen C.-N. (1989). Two stage screening in community. In Prevalence of Mental Disorders: Proceedings of the International Symposium on Psychiatric Epidemiology (ed. E.-K. Yeh, H. Rin, C.-C. Yeh and H.-G. Hwu). ROC Department of Health: Taipei (Taiwan).

Ciarlo J.A., Shern D.L., Tweed D.L., Kirkpatrick L.A. \& SachsEricsson N. (1992). II. The Colorado social survey of mental health service needs. Sampling, instrumentation, and major findings. Evaluation and Program Planning 15, 133-147.

Eaton W.W., Kramer M., Anthony J.C., Dryman A., Shapiro S. \& Locke B.Z. (1989). The incidence of specific DIS/DSM-III mental disorders: data from the NIMH Epidemiologic Catchment Area Program. Acta Psychiatrica Scandinavica 79, 163178.

Feighner J.P., Robins E., Guze S.B., Woodruff R.A., Winokur G. \& Munoz R. (1972). Diagnostic criteria for use in psychiatric research. Archives of General Psychiatry 26, 57-63.

Helzer J.E., Robins L.N., Croughan J.L. \& Welner A. (1981). Renard Diagnostic Interview. Its reliability and procedural validity with physicians and lay intervewers. Archives of General Psychiatry 38, 393-398.

Hwu H.-G., Yeh Y.-L., Wang J.-D. \& Yeh E.-K. (1990). Alcoholism among Taiwan aborigines defined by the Chinese Diagnostic Interview: a comparison with alcoholism among Chinese. Acta Psychiatrica Scandinavica 82, 374-380.

Karam E.G., Barakeh M. \& Karam A.N. (1991). The Arabic Diagnostic Interview Schedule. Revue Médicale Libanaise 3, 28-30.

Kovess V. \& Fournier L. (1990). The DISSA: An abridged selfadministered version of the DIS. Approach by episode. Social Psychiatry and Psychiatric Epidemiology 25, 179-186.

Lee C.K. (1992). Alcoholism in Korea. In Alcoholism in North America, Europe, and Asia (ed. JE. Helzer and G.J. Canino), pp. 247-263. Oxford University Press: New York.

Marcus S., Buka S. \& Robins L.N. (1990). A Data-Entry Program for DIS-III-R. St. Louis.

Marcus S., Robins L.N. \& Bucholz K.K. (1991). Computerized Quick Diagnostic Interview Schedule (QDIS3R). Washington University School of Medicine: St. Louis.

National Institute of Mental Health (1992). Diagnostic Interview Schedule for Children (DISC, Version 2). National Institute of Mental Health.

The President's Commission on Mental Health (1978). Report to the President, No. 040-000-00390-8. Gov. Printing Office: Washington, DC.
Rice J.P., Rochberg N., Endicott J., Lavori P.W. \& Miller C. (1992). Stability of psychiatric diagnoses. An application to the affective disorders. Archives of General Psichiatry 49, 824-830.

Robins L.N. \& Regier D.A. (ed.) (1991). Psychiatric Disorders in America. New York: Free Press, 1991.

Robins L., Helzer J., Croughan J., Williams J.B.W. \& Spitzer R.L. (1979). The NIMH Diagnostic Interview Schedule, Version II, with History and Introduction (1980), Instruction (1979), and Computer Programs (1980). ADM 42, 12.

Robins L.N., Helzer J.E., Cottler L. \& Goldring E. (1989). The Diagncstic Interview Schedule, Version III-A. St. Louis.

Spitzer R.L.. Endicott J. \& Robins E. (1978). Research diagnostic criteria. Rationale and reliability. Archives of General Psychiatry 35, 773-782.

Stefansson J.G., Lindal E., Bjornsson J.K \& Guomunddottir A. (1991). Lifetime prevalence of specific mental disorders among people born in Iceland in 1931. Acta Psychiatrica scandinavica 84, 142-149.

Wang C.-H., Liu W.T., Zhang M.Y., Yu E.S.H., Xia Z.Y., Fernandez M., Luang C.-T., Xu C.-L. \& Qu G.-Y. (1992). Alcohol use, abuse, and dependency in Shanghai. In Alcoholism in North America, Europe, and Asia (ed. J.E. Helzer and G.J. Canino), pp. 264-288, Oxford University Press: New York.

Wells J.E., Bushnell J.A., Hornblow A.R., Joyce P.R. \& OakleyBrowne M.A. (1989). Christchurch psychiatric epidemiology study, part 1: Methodology and lifetime prevalence for specific psychiatric disorders. Australian and New Zealand Journal of Psychiatry 23, 315-326.

Wittchen H.-U., Essau C.A. \& Krieg J.-C. (1991). Anxiety disorders: similarities and differences of comorbidity in treated and untreated groups. British Journal of Psychiatry 159, Suppl. 12, 23-33.

World Healt Organization, Editorial Committee (1993a). Composite International Diagnostic Interview, Version 1.l. American Psychiatric Press: Geneva.

World Health Organization, Editorial Committee (1993b). CIDIAUTO, Version 1.1. WHO Research and Training Center: Sydney.

World Health Organization, Editorial Committee (1993c), CIDIAUTO, Version 1.1. WHO Research and Training Center: St. Louis. 